minham para ultrapassar-lhe a "potencialidade".

Não apresenta, no entanto, nenhum caminho simples para as dificuldades com que se depara, apenas formula as questões básicas de tal modo a torná-las suscetiveis de abordagem pelos especialistas. 0 seu trabalho faz avançar a análise histórico-social retrospectivamente, dado que os problemas atuais não podem ser compreendidos desvin. culados de suas raizes, assina. lando o quadro das contradições formadas, pois somente a partir deste será possível erigir as linhas de uma nova base (teórica e prática), própria ao caso brasileiro.

E para completar nossa apreciação à obra de Caio Prado Jr., cumpre-nos ressaltar o seguinte: a referência a certos fatos mais recentes, feita pelo autor, poderiam eventualmente dar margem a questões como: a) não estariam tais fatos ainda comprometidos com a atual conjuntura, incorrendo o autor num possivel erro? b) a problemática proposta pelo autor, ou seja, o tratamento dado ao crescimento econômico e desenvolvimento, não faria parte também daquele remoinho próprio de situações político-econômico-sociais prestes a atingir seu ponto de saturação, na qual modelos, esforços, ideologias e as mais diversas proposições di142 gladiam-se sem encontrar saída?

Em nossa opinião, tanto uma quanto outra questão são improcedentes. Com relação à primeira, o autor supera o comprometimento, indo além da conjuntura, mostrando-se mais como um observador da estrutura. Elimina a idéia de que a distância no tempo é importante para a consideração serena dos fatos, impondo-se como um observador atento aos fatos que se sucedem diariamente, em profundidade.
Quanto à segunda, a idéia de tratar o problema sobre o desenvolvimento brasileiro, brota - e nisto não vemos nenhuma fonte de erro - dessa situação apontada; contudo, a problemática abordada é muito mais abrangente, no sentido de estar acima das proposições de soluções características desse tipo de conjuntura. Porque não se trata de mais uma salda para a questão, mas de propor que a teorização do problema seja articulada na própria praxis, isto é, no conjunto de fatos históricos concretos do qual faz parte. Aqui, a história não é vista como um fim em si mesmo, mas como um método de investigação necessário à formulação da teoria.

Por fim, o próprio subtítulo da obra História e desenvolvimento - A contribuição da historiografia para a teoria e prática do desenvolvimento brasileiro - indica o intento do autor de pôr em equação as linhas básicas desta problemática, através das forças históricas que lhe deram origem.

No entanto, limitamo-nos a comentar apenas do ponto de vista teórico, devendo esclarecer mais uma vez ter sido a parte prática, a história que o autor desenvolveu desde os inícios da colonização até 0 presente, que nos permitiu chegar a tais apreciações.

Cleide de Oliveira Vilăo

\section{Administração por objetivos: uma crítica}

Por João Bosco Lodi. São Paulo, Livraria Pioneira Editora, 1972. 119 p. Bibliografia. llustrado por Eduardo Östergren. Prefácio de 8 páginas.

Esta interessante obra de Lodi caracteriza-se por três fatores:

1. E uma primeira tentativa válida de criticar o sistema de administração por objetivos.

2. Revela ao público um grande desenhista de ilustrações de humor administrativo que faz falta em muitas obras sérias para desanuviar um pouco a extensão verbal do conceito apresen. tado sob forma impressa.

3. Apresenta uma bibliografia de 188 títulos sobre o assunto em pauta.

0 autor quer que os leitores tenham lido o seu livro anterior. De fato, um conhecimento básico sobre ApO é necessário para não se perder o fio da meada dentro de uma obra, cujos três capitulos e duas entrevistas estão com um nexo relativamente tênue: 
Capítulo 1: A administração por objetivos no Brasil;

Capítulo 2: Sete casos para o estudo de objetivos;

Capítulo 3: Objetivos: vantagem ou ameaça?

Entrevista: A técnica de administrar por desafios (Expansão 4 de abril de 1972);

Entrevista: Perspectiva brasileira (Sino Azul, CTB - house organ, ano 4, n. 9, maio/jun. 1972).

- Prof. Lodi não passou de papa brasileiro a antipapa da administração por objetivos por meio desta obra; longe disso, ele só procura na crítica uma explicação para o fracasso do sistema de procedimentos por objetivos em algumas empresas e os motivos do sucesso em outras. Assim, em teoria semântica, o titulo do livro faz jus ao conteúdo, já que crítica, em sentido largo, é "arte de julgar o valor", "faculdade de distinguir do erro a verdade", "sistema de distinção do certo e errado", etc. Preferencialmente, o livro deveria ser chamado "uma pesquisa sobre vantagens e desvantagens, procedimentos certos e errados" - pois o título "crítica" dá a entender que se julgue o valor, que não é criticado; no entanto, 0 autor continua na opinião firme de que a administração por objetivos é um procedimento válido, quando bem introduzido e aplicado numa empresa bem estruturada. Nesse ponto o resenhista compartilha a opinião do autor.

O livro, no entanto, não critica clàramente um aspecto primordial da administração por objetivos: "o fim justifica os meios", isto é, o administrador pode ir sobre cadáveres para chegar ao objetivo. Ou, em sentido verdadeiro, o autor cita, para atingir determinado objetivo, passar os prazos de pagamentos de 75 para 85 dias. 0 resenhista tem pleno conhecimento de como isso é conseguido por meio de pressão sobre os fornecedores mais fracos - chegando ao ponto de declarar "fornecedor inidôneo" um fornecedor que ousou protestar um título da tal empresa forte, após decorridos, sem pagamentos, 60 dias da data marcada para saldar a dívida, cujo prazo, por si só, já estava além do habitual no comércio. Pode ser bom para a empresa, mas será de interesse social, nacional ou mesmo administrativo a longo prazo?

Não concorda o resenhista com a definição de que a Apo é um neotaylorismo (Levinsohn), pois Levinsohn deve ter levado em conta, no momento em que escreveu, o fato da fixação dos "objetivos" dos conglomerados norte-americanos - exemplos clássicos de objetivos fixos para as necessidades da administração central, de cima para baixo. Também não chamo ApO ao que acontece na fixação de objetivos de multinacionais, nas quais um objetivo real é fixo pelo segundo escalão (brasileiro) plenamente alcançável, vamos dizer, $12 \%$ de aumento de vendas em unidades. Quando a diretoria local vê tal objetivo, o aumento vai para $15 \%$, como medida não baseada em dados de pesquisa, mas como meta incentivadora. Quando voltou do país, sede da multinacional, o objetivo foi colocado em $18 \%$ ou até $20 \%$ - e isso figura como uma revisão das estimativas do pessoal propondo, como objetivo, a redução de $8 \%$ da mão-de-obra e cortando os investimentos para reformar máquinas e compra de automatismos.

Aliás, a melhor crítica do livro ao sistema ApO se encontra nas notas de rodapé das $p$. 77-8, quando Lodi critica o sistema como desumanizante, mas não dá continuidade a tal crítica no texto.
Os perigos da ApO são colocados na entrevista da p. 96 e vale a pena citá-los aqui:

a) irritação, hostilidade e perda do cliente;

b) crises pessoais;

c) oportunismo e desprezo pelos meios;

d) individualismo e falta de colaboração.

As limitações do sistema são enumeradas na p. 103, quando Lodi mostra a falta de afinidade da administração por objetivos e empresas de natureza científica ou intelectual. Infelizmente, aqui mesmo muita gente procura aplicá-la, obtendo resultados já visiveis: má qualidade do trabalho e encobrimento de falhas. Entretanto, existem vantagens: definitivamente evita que o pesquisador ultrapasse o limite (paridade) entre o custo de esforço e resultado da pesquisa, pois o acréscimo marginal dos conhecimentos, a partir de certo tempo, não paga o esforço de pesquisa.

O livro explica parcialmente a maior problemática do procedimento: os conflitos entre objetivos, tanto entre os de finanças e vendas como entre os de produção (este assunto está omisso na apreciação, da p. 107, e é justamente a área de maior conflito). Objetivos conflitantes seriam, por exemplo:

produção - máximo de produção;

vendas - máximo de faturamento e lucro inclusive por exportação.

Não necessariamente, os produtos mais vendidos serão aqueles que darão maior produtividade na produção e também não serão os mais lucrativos. A exportação é, muitas vezes, realizada dentro da técnica de fixar 
um preço de venda externa para dar margem de contribuição e não lucro, o que parece deficitário ao controlador da empresa. $E$ assim vão os conflitos. A idéia de Lodi de resolver os conflitos por meio de fixação de objetivos comuns é realista e possível.

0 autor se preocupa com o que virá depois da administração por objetivos. Acreditará Lodi que ela não passa de moda como a zero defects, TWI, etc.? A preoєupação do autor não é compartilhada pelo resenhista - ele se pergunta se os resultados obtidos na Souza Cruz, Sambra, Banco Real etc. não poderiam ter sido obtidos também sem a ApO.

Resumidamente, trata-se de um ótimo livro que se lê com muito agrado numa chuvosa tarde de domingo ou durante uma viagem aérea. A bibliografia está otima e Humble e Peter Drucker, os profetas do sistema, estão muito bem representados. A critica é pouca, mas a avaliação está bem feita; as caricaturas são divertidas, mas pouco relacionadas ao texto. Recomenda-se a leitura desta obra a todos aqueles que já se entusiasmaram com o sistema e vão colocá-lo em funcionamento e aos já administra. dos por objetivos e seus administradores; convém, contudo, que leiam antes a obra anterior de João B. Lodi, Administração por objetivos. 0 presente livro, na opinião do resenhista, é muito útil para administração pública na avaliação dos métodos de fixação de objetivos da polltica de planejamento e infra-estruturas, exportação etc.

Muito boa a apresentação gráfica. A brochura é suficiente para um livro tão leve como este.

Kurt E. Weil

\section{EONTARUDATE TE EUSTOS}

\section{PRODUGÃO}

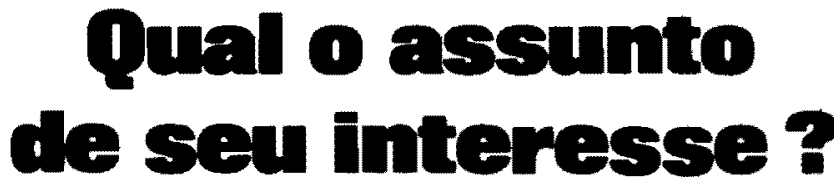

Custos - UM ENFOQUE

abministrativo de George S.

Guerra Leone $\left(2 .^{\circ}\right.$ edição. revista) - Um livro sobre contabilidade de custos destinado a professores e alunos das escolas de administração, a gerences financeiros e tantos quantos lidem com custos e análise contabil e financeira.

\section{Peseuisa mercadologica}

de Boyd Westuall (2. ${ }^{\circ}$ ed.) .

Apresenta projetos de pesquisa e métodos para a coleta de dados junto ao mercado consumidor. aborda detalhadamente as fases de seu desenvolvimento, detendo-se nos metodos de amostragem aplicados à mercadização.

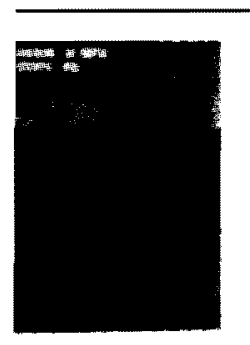

manual de administracho da prooucho de Machline, Weil, Sa Motza e Schoeps ( 2 volumes) A orientação cientifica, o tratamento prospectivo dos temas. a preocupação com a awalização do quadro administrativo brasileiro e - sobretudo - a pertinente adequação dos temas à nossa realidade tornam este manual imprescindivel a todo administrador industrial. 